\title{
Influence of Electron Beam Irradiation on Bending Fracture Stress for Soda Glass*1
}

\author{
Yoshitake Nishi, Atsushi Kadowaki*2 and Tomohiro Sinoda*2 \\ Department of Materials Science, Tokai University, Kanagawa 259-1292, Japan
}

To study the effects of electron beam (EB) irradiation on the bending stress-strain curves for soda glass, we measured these curves by a standard bending test. EB irradiation enhanced bending fracture stress and rigidity of the glass, and also extended the crack length of a homogeneously fractured sample. When the EB irradiation generated dangling bonds at the weaker-bonded metal-oxygen atomic pairs in the soda glass network structure, partial relaxation occurred at points of residual strain in the network structure. Evidently the increased rigidity was mainly due to an increase in the bonding energy for the silicon-oxygen atomic pairs in the atomic network structure. The irradiation also eliminated the crack origin points in the homogeneously fractured soda glass, thus inducing a high fracture stress.

(Received August 10, 2004; Accepted October 22, 2004)

Keywords: electron beam, fracture stress, bending, inorganic, glass

\section{Introduction}

An electron curtain processor, an apparatus used in homogeneous electron beam (EB) irradiation, and generally to enhance polymer sterilization and hardening, is a successful device for certain surface treatments. To control physical properties such as wetting, and freedom from misting and to facilitate the fracture-free sterilization of glassy ceramics, electron beam irradiation techniques are presently being developed to assist the production of dentists' mirrors, sapphire lenses for endoscopes, diamond windows, and silica glass. ${ }^{1-4)}$ Recently, EB reinforcement methods have been established for carbon fiber (CF), carbon deposited carbon fiber $(\mathrm{C} / \mathrm{C})$ composite materials and carbon fiber reinforced polymer (CFRP).$^{5-9)}$ However, another effect of EB irradiation is the homogeneous activation of surface atoms and the breaking of the chemical bonds between the $\mathrm{Si}-\mathrm{O}$ pairs in the network structure of a surface layer of silica glass. ${ }^{4}$ By this means, such irradiation induces a resistance to fracture under loading in the tightly bonded network structure of silica glass. ${ }^{10,11)}$

To evaluate the load resistances to elastic and plastic deformations and fracture stress and strain, a knowledge of the stress-strain curve is important. If EB-irradiation controls crack generation, it should enhance the fracture stress. To confirm the idea that we can strengthen transparent ceramics even after solidification, we have undertaken the present study to investigate the possible beneficial effects of EB irradiation on the fracture stress and fracture strain of soda glass. To clarify the phenomena, we used ESR observations to confirm the existence of predicted dangling bonds.

\section{Experimental}

\subsection{Electron beam irradiation}

The sizes of our soda glass samples (micro-cover glass, Matsnami Glass Ltd. Japan) were $24 \mathrm{~mm} \times 24 \mathrm{~mm} \times$

\footnotetext{
${ }^{* 1}$ This Paper was Originally Published in Japanese in J. Japan Inst. Metals 68 (2004) 202-205.

${ }^{* 2}$ Graduate Student, Tokai University.
}

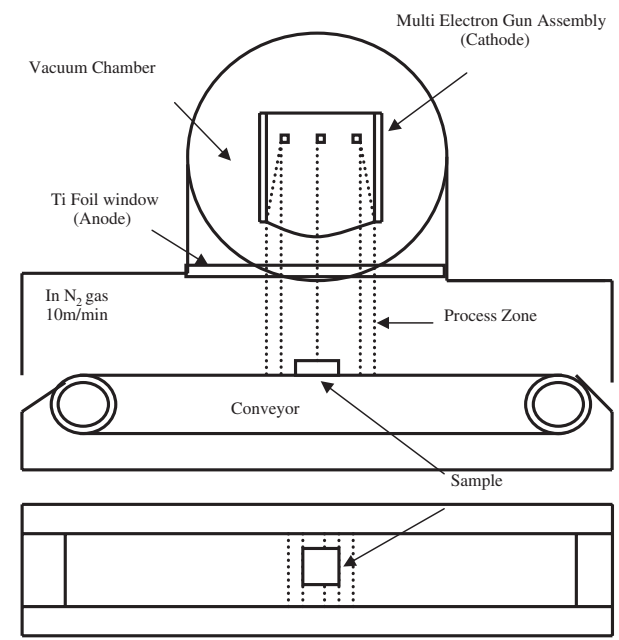

Fig. 1 Schematic diagram of Electron Curtain Processor.

$0.145 \pm 0.005 \mathrm{~mm}$. An ESCA analysis (time/step: $40 \mathrm{~ms}$, probe diameter: $100 \mu \mathrm{m}$, Pass potential: $23.5 \mathrm{eV}$, Step: $0.1 \mathrm{eV}$, Sweeps 20,1 kV-30s) showed that the chemical composition ratio of their metal elements (Si:Na:K:Al: $\mathrm{Mg}: \mathrm{Zn}$ ) were 70.5:13.2:7.6:5.9:1.8:1.0, respectively.

The glass sheets were homogeneously irradiated using an electron-curtain processor (Type CB175/15/180L, Energy Science Inc., Woburn, MA, Iwasaki Electric Group Co. Ltd. Tokyo). ${ }^{1-11)}$ Figure 1 shows the schematic diagram of the apparatus. The specimen was homogeneously irradiated by the electron beam through a titanium thin film window attached to the vacuum chamber $(240 \mathrm{~mm}$ in diameter). A tungsten filament in vacuum generated the electron beam using an acceleration potential of $170 \mathrm{kV}$ and an irradiating current of $2.0 \mathrm{~mA}$. In order to prevent oxidation, the samples were kept under the protection of one atmosphere of nitrogen gas having a residual concentration of oxygen below $400 \mathrm{ppm}$. The flow rate of the nitrogen gas was $10 \mathrm{~L} / \mathrm{s}$ at $0.1 \mathrm{MPa}$ of nitrogen gas pressure. Each dose of EB irradiation was applied for only a short time $(0.23 \mathrm{~s})$ to avoid excessive heating of the sample; the temperature of the surface of the sample was below $323 \mathrm{~K}$ just after irradiation. The sample in 
the aluminum plate holder $(0.15 \mathrm{~m} \times 0.15 \mathrm{~m})$ was transported on a conveyor at a speed of $9.56 \mathrm{~m} \cdot \mathrm{min}^{-1}$. Repeated applications were used to increase the total dose of irradiation. The interval between the end of one period of irradiation and the start of the next irradiation was $30 \mathrm{~s}$. The dosage was proportional to the yield value determined from the irradiation current $(I, \mathrm{~mA})$, the conveyor speed $(S$, $\left.\mathrm{m} \cdot \mathrm{min}^{-1}\right)$, and number of irradiations $(N)$. The yield value was calibrated by FWT nylon dosimeters (Far West Technology, Inc. 330-D South Kellogg Goleta, California 93117, Califolnia).

Based on the density $\left(\rho: \mathrm{kg} / \mathrm{m}^{3}\right)$ and irradiation voltage $(V$ : $\mathrm{kV})$, the EB-irradiation depth $\left(D_{\mathrm{th}}: \mathrm{m}\right)$ is expressed by the following equation. ${ }^{12)}$

$$
D_{\text {th }}=66.7 V^{5 / 3} / \rho
$$

The surface electrical potential $(128 \mathrm{keV})$ was estimated from the electrical potential $(170 \mathrm{keV})$, the thickness of the titanium window $\left(10 \mu \mathrm{m}\right.$; density: $\left.4540 \mathrm{~kg} / \mathrm{m}^{3}\right)$ and the distance in the nitrogen gas atmosphere $(30 \mathrm{~mm}$; density: $1.13 \mathrm{~kg} / \mathrm{m}^{3}$ ) between the sample and the window. Since the measured density for soda glass was $2430 \mathrm{~kg} / \mathrm{m}^{3}(2.43 \mathrm{~g} /$ $\mathrm{mL}$ ), the EB-irradiation depth estimated from (1) should have been $9.16 \times 10^{-5} \mathrm{~mm}(91.6 \mu \mathrm{m})$ for this material.

\subsection{Bending test to evaluate rigidity and fracture stress}

To evaluate the rigidity and fracture stress, the stress-strain curves of the glasses with and without EB irradiation were measured by a standard Ewing optical strain measurement system (JIS R 1601-1995). Figure 2 shows a schematic drawing of the strain measurement system (a) and the bending test (b). The strain $(\varepsilon)$ was estimated by the following equation:

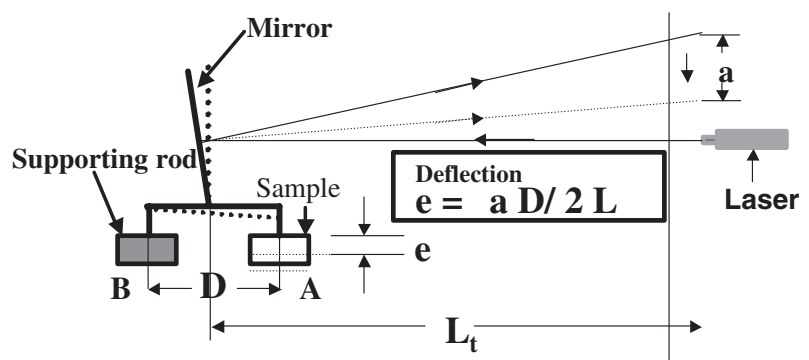

(a)

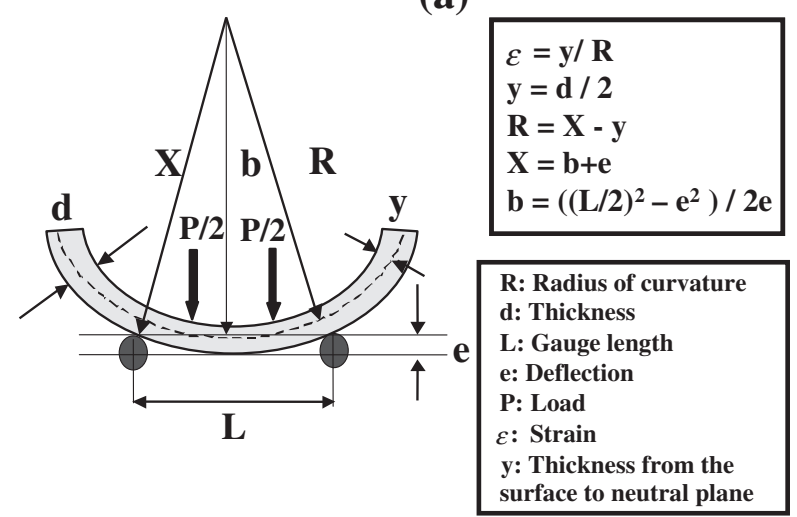

(b)

Fig. 2 Schematic drawings of Ewing optical strain measurement system (a) and bending test (b).

$$
\varepsilon=e d /\left((L / 2)^{2}-e^{2}+2(e-y)\right)
$$

Here, $e(\mathrm{~mm}), d(\mathrm{~mm}), L(\mathrm{~mm})$ and $y(\mathrm{~mm})$ are deflections estimated, respectively, from the sample thickness, the gauge length, and the thickness from the surface to the neutral plane. When the values $X(\mathrm{~mm})=(R+y)$ and $e(\mathrm{~mm})=$ $(X-b)$ are measured, the radii of curvature $R(\mathrm{~mm})$ and $b$ $(\mathrm{mm})$ are obtained. The bending stress $\sigma(\mathrm{MPa})$ is then expressed by the following equation:

$$
\sigma=3 P\left(L-L_{\mathrm{u}}\right) / 2 w t^{2}
$$

Here, $P(\mathrm{~N}), L_{\mathrm{u}}(\mathrm{mm}), w(\mathrm{~mm})$ and $d(\mathrm{~mm})$ are the load, the upper gauge length between the loading points, the sample width and the sample thickness, respectively.

\subsection{Evaluation of dangling bonds}

To obtain more precise information on atomic-scale structural changes in the glass, the density of the dangling bonds in a sample was obtained using an electron spin resonance spectrometer (ESR, JES-FA2000, Nippon Dennshi Ltd., Tokyo). ${ }^{1,6,10,11)}$ The microwave frequency range used in the ESR analysis was the X-band at $9.45 \pm 0.05 \mathrm{GHz}$, with a field modulation of $100 \mathrm{kHz}$. The spin density was calculated using a $\mathrm{Mn}^{2+}$ standard sample.

\section{Results}

Two types of fractured samples were recognized: homogeneously and heterogeneously fractured. Figure 3 shows both types of fractures in our soda glass samples. If the

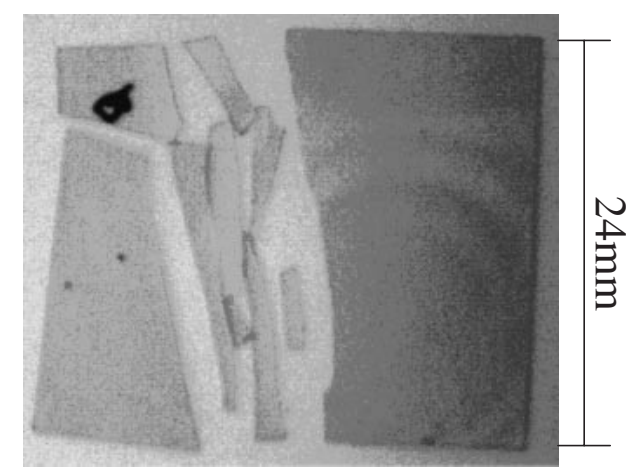

(a)

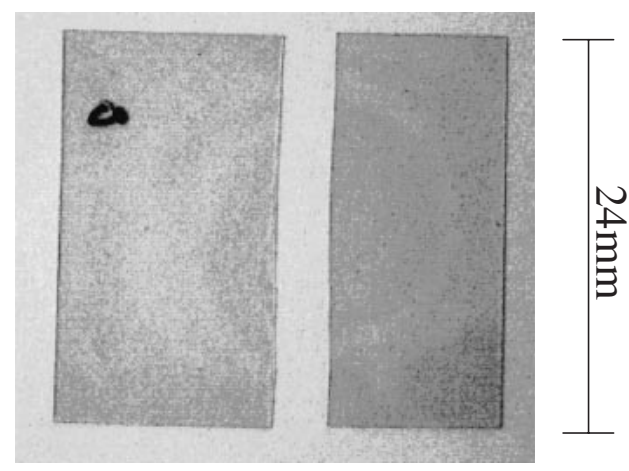

(b)

Fig. 3 Photographs of homogeneously (a) and heterogeneously (b) fractured soda glass samples. 


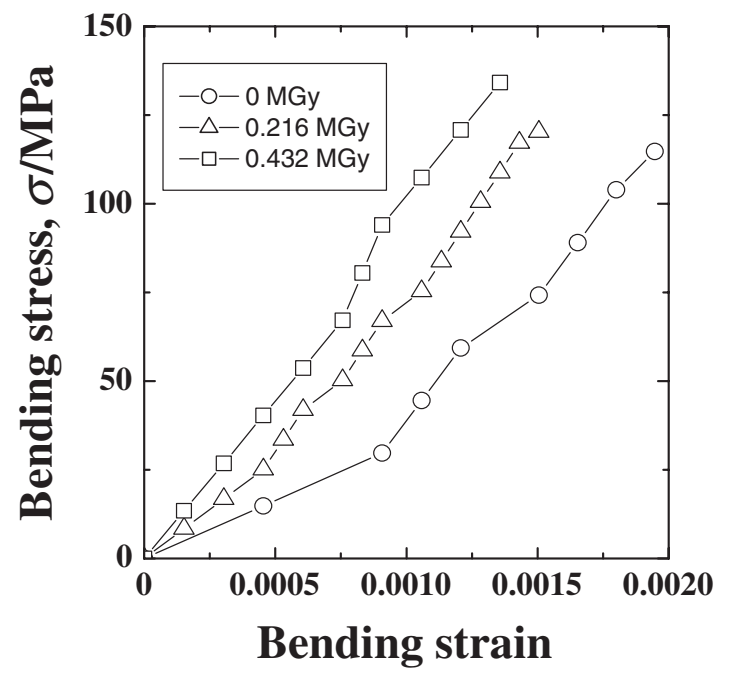

Fig. 4 Stress-strain (S-S) curves of homogeneously fractured samples at different EB irradiation dosed.

sample contains no spontaneous crack, it should fracture homogeneously, as shown in Fig. 3(a). In heterogeneously fractured glass, EB irradiation appears to have no effect on fracture stress. The heterogeneously fractured samples were divided into two pieces; the breakage occurred just at spontaneous crack origins on the samples, as shown in Fig. 3(b). Thus, to evaluate the apparent effects of EB irradiation, we prepared crack-free and homogeneously fractured samples for the bending test.

Figure 4 shows stress-strain (S-S) curves of homogeneously fractured samples at different EB irradiation dosages. The electron beam apparently enhanced the slope and linearity of the $\mathrm{S}-\mathrm{S}$ curves. The electron beam also increased the fracture stress, but decreased the fracture strain. Thus, the EB irradiation doses enhanced the rigidity and fracture stress as hoped.

From the general X-ray diffraction patterns of the soda glass before and after EB treatment, we could observe no remarkable structure changes. On the other hand, the EB irradiation did produce detectable dangling bonds with free volume. Figure 5 shows the ESR signals of different soda glasses before and after EB irradiation. In irradiated soda glass, we noted a high density of dangling bonds. A sharp ESR signal was observed in irradiated silica glass ${ }^{10,11)}$ corresponding to dangling bonds of an E-prime center consisting of an $\mathrm{Si}-\mathrm{O}$ pair; ${ }^{13,14)}$ therefore the large signal in the EB-irradiated soda glass should originate in weaklybonded metal (Na, K, Mg, Zn)-oxygen pairs. Evidently, EBirradiation generated the dangling bonds of weakly-bonded pairs in the glassy network structure.

\section{Discussion}

\subsection{Fracture stress enhancement by crack origin anni- hilation due to $\mathrm{EB}$ irradiation}

As demonstrated in Fig. 6 (dotted line), we found a reinforcement of the fracture stress of the soda glass samples from $114 \mathrm{MPa}$ before $\mathrm{EB}$ irradiation to $134 \mathrm{MPa}$ after $0.432 \mathrm{MGy}$ of EB irradiation. An increase was about $20 \%$.

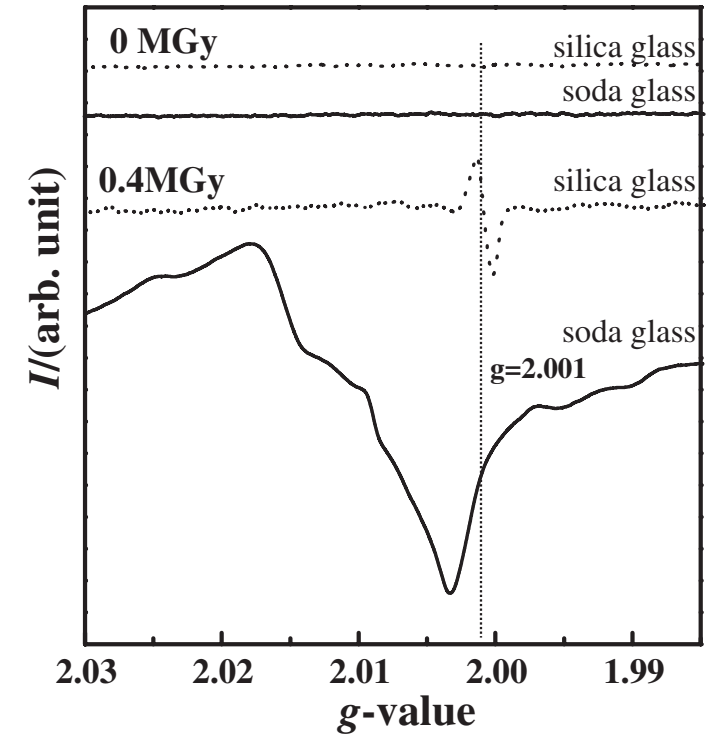

Fig. 5 ESR signals of different soda and silica glasses before and after EB irradiation.

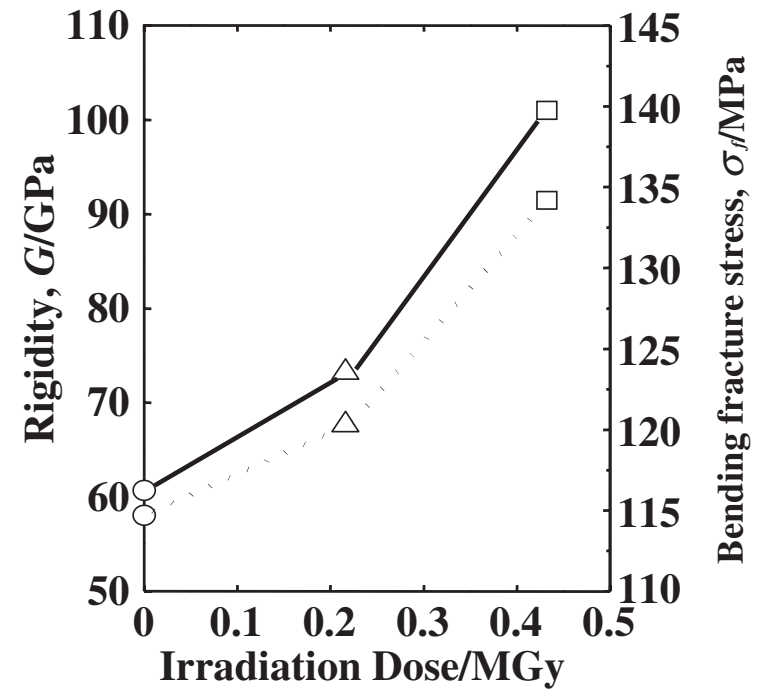

Fig. 6 Changes in rigidity (solid line) and bending fracture stress (dotted line) of soda glass against EB-irradiation dose.

Figure 7 shows the change in the crack length in soda glass samples with EB irradiation dose. The solid and dotted lines represent the homogeneously and heterogeneously fractured samples, respectively. Although the crack length of the heterogeneously fractured samples didn't depend on the irradiation dose, EB irradiation did extend the crack length of the homogeneously fractured soda glass. If the EB irradiation decreased the number of spontaneous cracks in the samples, it also elevated the fracture stress. Thus, the removal of crack origin points explains one of the apparent effects of EB irradiation on fracture stress.

\subsection{EB-induced enhancement of rigidity via dangling bond formation}

As shown in Fig. 6 (solid line), we also noted an enhancement in rigidity from 60 to $100 \mathrm{GPa}$ after 0.432 


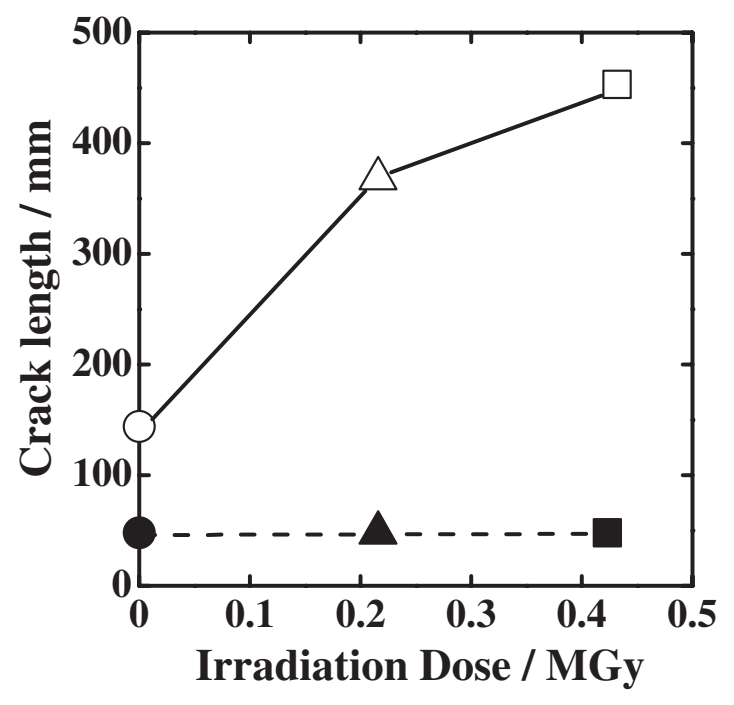

Fig. 7 Change in crack length in soda glass against EB irradiation dose. Dotted and solid lines are for heterogeneously and homogeneously fractured samples with and without crack origin points, respectively.

MGy of irradiation of the soda glass. The electron beam increased the rigidity of the glass to a level about $60 \%$ above that of the sample before irradiation.

Since the annealed structure of the soda glass was that of a tightly bonded network, the soda glass was brittle. If the relaxation of the molecular stress in silica glassy network structure is due to the EB-created free volume, originating in dangling bonds of weakly-bonded metal-oxygen pairs, as shown in Fig. 5, the EB irradiation probably intensified the rigidity in the soda glass.

\section{Conclusion}

In the EB-irradiated soda glass, the observed increased rigidity can be explained by the strengthening of the silica based network induced by the formation of dangling bonds in weakly-bonded metal-oxygen atom pairs. The high fracture stress evidently results from crack origin annihilation in the irradiated, homogeneously fractured soda glass.

\section{Acknowledgements}

The author would like to thank Prof. Akira Tonegawa, Dr. Kazuya Oguri, Mr. Naoki Yamaguchi and Mr. Kousuke Takahashi of Tokai University for their useful assistance.

\section{REFERENCES}

1) Y. Nishi, K. Oguri, K. Fujita, M. Takahashi, Y. Omori, A. Tonegawa, N. Honda, M. Ochi and K. Takayama: J. Mater. Res. 13 (1998) 33683371.

2) K. Oguri, N. Iwatani, H. Izumi, A. Tonegawa, K. Takayama and Y. Nishi: Proc. of 2nd Japan-France Semi. on Intelligent Materials and Structures, 1998) 142-144.

3) K. Oguri, N. Iwataka, A. Tonegawa, Y. Hirose, K. Takayama and Y. Nishi: J. Mater. Res. 16 (2001) 553-557.

4) K. Oguri, K. Sato, T. Izumi, A. Tonegawa, K. Takayama and Y. Nishi: Mater. Res. Soc. Sympo. Proc. 540 (1999) 261-265.

5) Y. Nishi, T. Toriyama, K. Oguri, A. Tonegawa and K. Takayama: J. Mater. Res. 16 (2001) 1632-1635.

6) Y. Nishi, A. Mizutani, A. Kimura, T. Toriyama, K. Oguri and A. Tonegawa: J. Mater. Sci. 38 (2003) 89-92.

7) Y. Nishi, N. Uchida, A. Kimura, A. Mizutani, K. Oguri and A. Tonegawa: J. Mater. Sci. 38 (2003) 2215-2218.

8) A. Mizutani and Y. Nishi: Mater. Trans. 44 (2003) 1857-1860.

9) Y. Nishi, A. Mizutani and N. Uchida: J. Thermoplastic Composite Materials 17 (2004) 289-302.

10) N. Yamaguchi, K. Oguri, A. Tonegawa and Y. Nishi: J. Japan Inst. Metals 68 (2004) 198-201.

11) Y. Nishi and K. Oguri: Mater. Trans. 45 (2004) 1903-1906.

12) G. Wakalopulos: Radtech Report, July/August (1998) 10-15.

13) D. L. Griscom and E. J. Friebele: Rad. Effects 65 (1982) 303-312.

14) D. L. Griscom: The Centenial Memorial Issue of the Ceramic Soc. Jpn. 99 (1991) 923-942. 